\title{
Competition between three estuarine benthic diatom species in mixed cultures*
}

\author{
Loes de Jong and Wim Admiraal
}

\author{
Department of Marine Biology, State University of Groningen, P.O. Box 14, 9750 AA Haren, The Netherlands
}

\begin{abstract}
Three species of intertidal diatoms were kept in unialgal and mixed cultures forming mats on the surface of clean sand. Interaction between the species was studied by $25 \mathrm{~d}$ incubation in serially diluted cultures, allowing natural population densities to be maintained. Abundance of species in mixed cultures was primarily determined by their capacities to thrive under inorganic carbon limitation (and associated conditions) and by their capacity to produce inhibitory substances. The range of physico-chemical conditions exploited by the test species narrowed considerably during interaction with a competitor. The relevance of the experiments for the interpretation of distribution patterns of estuarine diatom species is discussed as is the limited information available on mechanisms for carbonfixation in these organisms.
\end{abstract}

\section{INTRODUCTION}

Estuarine intertidal flats are often inhabited by rich diatom communities. The structure of fresh-water diatom communities proved to be largely determined by available species pool, invasion rate, grazing pressure, parasitism and competition (Patrick, 1977). Some of these factors have been studied in detail in relation to benthic diatom species living on the surface of estuarine tidal flats. Among the many density-independent factors the influences of light intensity, temperature, nutrient levels, salinity and stress factors have been examined in the Eems-Dollard estuary (Admiraal and Peletier, 1980).

It was found that most species generally survive and grow under broad ranges of physico-chemical conditions when grown in unialgal cultures, and yet they showed well-defined patterns of seasonal and spatial distribution (Colijn and Dijkema, 1981; Admiraal et al., 1984). The present study analyzes the question whether density-dependent factors might explain this apparent contradiction. A culture study on dense unialgal mats of some of the dominant species (Admiraal et al., 1982) showed that photosynthesis was reduced because of insufficient supply of inorganic carbon,

\footnotetext{
- Publication No. 84 of the project 'Biological Research EemsDollard Estuary'
}

mainly bicarbonate. Furthermore, in these dense films an inhibiting effect of oxygen was measured: this resulted in the high photosynthetic production of oxygen. Until now this 'crowding' effect has attracted little attention but it is thought to play an important role in determining species composition in natural populations.

Competitive interactions between micro-algae have almost exclusively been studied in phytoplankton cultures (e.g. Fedorov and Kustenko, 1972; Lange, 1974; Russell and Fielding, 1974; Elbrächter, 1977; Tilman, 1978; Kayser, 1979; Sharp et al., 1979). The use of suspension cultures, as in these earlier investigations, is not applicable to benthic algae, where the packing of several cell layers itself is an essential prerequisite. A suitable culture technique was found in the serially renewed or semi-continuous culture (Admiraal et al., 1984), in which the diatoms are allowed to develop their characteristic mats but can be kept at the preferred densities by a dilution regime, allowing a controlled increase in cell number. Mixed cultures of 3 species kept under these culture conditions were subjected to a range of different conditions of salinity, temperature and supply of inorganic carbon. The responses of the individual species in mixed and unialgal cultures are compared and from this the role of interspecific interaction in determining the distribution of diatom species over the estuarine gradient is discussed. 


\section{MATERIAL AND METHODS}

Axenic cultures of Navicula salinarum Gr. and Nitzschia closterium (Ehr.) W. Sm., together with a non-axenic culture of Amphiprora cf. paludosa W. Sm., were used for experiments. Numbers of bacteria in cultures of the latter species always remained low. All organisms were isolated from sediments of the EemsDollard estuary. Mean cell volumes of $N$. salinarum, $N$. closterium and $A$. cf. paludosa were 600, 150 and $3,000 \mu \mathrm{m}^{3}$ respectively; their chlorophyll a contents under standard culture conditions are 2.1, 1.0 and $5.2 \mathrm{pg} \mathrm{cell}{ }^{-1}$ respectively. A synthetic seawater medium was prepared from a stock solution containing the following salts: $\mathrm{NaCl} 2,096.2 \mathrm{mM}, \mathrm{MgCl}_{2} \cdot 6 \mathrm{H}_{2} \mathrm{O}$ $241.1 \mathrm{mM}, \mathrm{CaCl}_{2} .2 \quad \mathrm{H}_{2} \mathrm{O} 18.0 \mathrm{mM}, \mathrm{Na}_{2} \mathrm{SO}_{4} .10 \quad \mathrm{H}_{2} \mathrm{O}$ $122.1 \mathrm{mM}$ and $\mathrm{K}_{2} \mathrm{SO}_{4} 24.4 \mathrm{mM}$. This stock solution (with a salinity of $168.5 \%$ ) was diluted with demineralized water to obtain the desired salinity. To complete the medium the following nutrients were added: $\mathrm{NH}_{4} \mathrm{Cl} 0.25 \mathrm{mM}, \mathrm{KNO}_{3} 0.68 \mathrm{mM}, \mathrm{NaH}_{2} \mathrm{PO}_{4}$. $\mathrm{H}_{2} \mathrm{O} 0.02 \mathrm{mM}, \mathrm{NaSiO}_{3} .9 \mathrm{H}_{2} \mathrm{O} 0.12 \mathrm{mM}$ and $\mathrm{NaHCO}_{3}$ $1.1 \mathrm{mM}$. Trace elements and vitamins were added as described earlier (Admiraal et al., 1982). The $\mathrm{pH}$ of the medium was 8.0 to 8.3 . To prevent precipitation the solutions of phosphate, silicate and trace elements were autoclaved separately and added aseptically. Fluorescent tubes (Philips TL-F 40 W/34) were placed above the cultures; they maintained a quantum irradiance of $125 \mu \mathrm{E} \mathrm{m}^{-2} \mathrm{~s}^{-1}$ at the surface of the algal layers during the daily photoperiod of $8 \mathrm{~h}$. Algae were grown on a 3 to $4 \mathrm{~mm}$ thick layer of analytically clean sand (Merck) under $5 \mathrm{~cm}$ of medium in $60 \mathrm{ml}$ serum bottles.

Air and fresh medium were supplied to the cultures in various regimes: (1) Stagnant culture without aeration and medium renewal; (2) stagnant culture with a step-wise dilution of the medium and algal population (see below); (3) continuously aerated culture with stepwise dilution; (4) continuously aerated culture with continuous renewal of medium and step-wise dilution of the diatom population. The growth of the cultures kept under Regimes 2, 3 and 4 did not differ greatly. Therefore the simple Regimes 2 and 3 were chosen for our competition experiments.

The culture regime used may be referred to as a semi-continuous culture, as it was based on the regular dilution of a batch culture. A period of growth lasting 3 to $5 \mathrm{~d}$ was followed by the removal of $50 \%$ of the diatom cells together with $50 \%$ of the culture medium: they were replaced by an identical volume of fresh medium. Before this dilution the cells were suspended and after the new medium had been added the cells were allowed to settle again on the sand substrate. Aeration of the culture did not disturb the algal mat once it was established. Continuing this procedure for several periods resulted in a more or less constant growth rate of the algal population; its density and doubling frequency depended on the dilution rate and the length of the growth period. In this way it was possible to maintain density and growth rate at the desired levels. Unialgal and mixed cultures were subjected to a similar series of experiments, in order to test the effects of various temperatures $\left(8,12,20^{\circ} \mathrm{C}\right)$ and salinities ( 1 to $34 \%$ ). Earlier experiments (Admiraal et al., 1982) had shown the importance of inorganic carbon supply in dense cultures. Therefore we compared the effect of the standard supply of inorganic carbon with the effect of a lower supply and of an increased supply. To decrease the supply of inorganic carbon we lowered the initial $\mathrm{NaHCO}_{3}$ concentration in the medium from 1.1 to $0.3 \mathrm{mM}$, whereas to increase the supply, we added $6 \mathrm{mM} \mathrm{NaHCO}$ to the medium and enriched the airstream with $1 \% \mathrm{CO}_{2}$.

Population densities in the cultures were determined by cell counts. At least 200 cells were counted in a microscopic counting chamber (depth $0.1 \mathrm{~mm}$ ).

\section{RESULTS}

Fig. 1 shows the effect of the incubation conditions on monocultures of the three diatom species. An increased supply of bicarbonate stimulated growth of the cultures, especially at higher population densities, confirming earlier observations on inorganic carbon limited growth (Admiraal et al., 1982). Step-wise dilution of cultures led to population densities that fluctuated around a more or less stable value, although one of the Amphiprora cf. paludosa cultures seems not to equilibrate within the experimental period. This indicates that in most cases the conditions required for the late exponential and early stationary growth phase can be maintained over a long period of time in semicontinuous cultures. The mean growth rate under these conditions was 1 cell division per $3 \mathrm{~d}$, whereas the populations complete more than 1 cell division per day at low densities. The population densities observed under step-wise dilution (Fig. 1) reached levels normally found in well developed natural populations. Chlorophyll a content of these cultures ranged between 20 and $100 \mathrm{mg} \mathrm{m}^{-2}$. When cultured under similar conditions the 3 test species reached similar population densities, as measured by the chlorophyll a concentration. In the light and especially under ample supply of bicarbonate the diatom films developed gas bubbles, most likely composed of oxygen-enriched air. In the stagnant water layer over a dense mat of diatoms $\mathrm{pH}$ values up to 9.9 were measured. Hence, we must assume that the growth limitation in the step-wise 


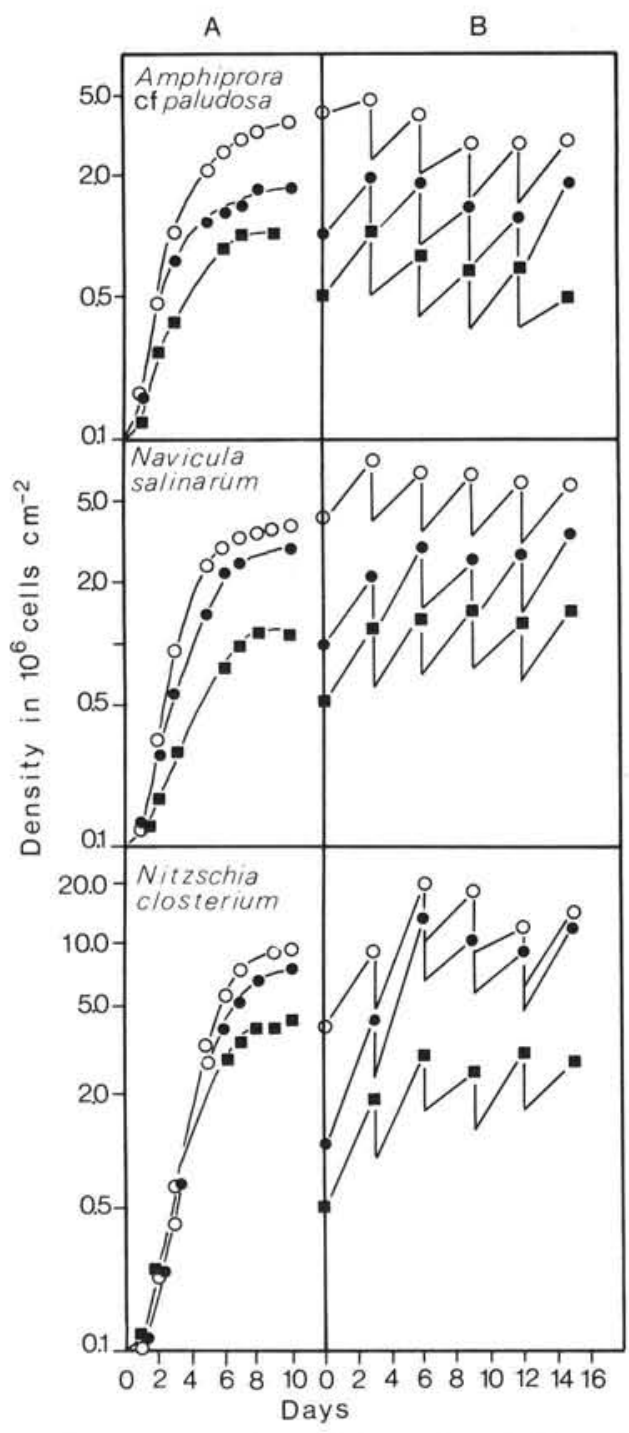

Fig. 1. Amphiprora cf. paludosa, Navicula salinarum, Nitzschia closterium. Growth curves of unialgal batch (A) and serially diluted (B) cultures. Standard supply of inorganic carbon; $\bigcirc$ : increased supply of inorganic carbon; : decreased supply of organic carbon (see 'Material and Methods'). Temperature: $20^{\circ} \mathrm{C}$; salinity: $15 \%$

diluted culture is determined by a combination of 3 related factors: depletion of substrate $\mathrm{HCO}_{3}{ }^{-}$, accumulation of high concentrations of $\mathrm{O}_{2}$ and rise of $\mathrm{pH}$ (for discussion see Admiraal et al., 1982). In the present experiments these conditions were tested in 3 gradations, introduced arbitrarily by varying the supply of bicarbonate and carbon dioxide.

A series of competition experiments was carried out by maintaining mixtures of species under step-wise dilution for at least $25 \mathrm{~d}$ under a series of different conditions. Fig. 2 shows the results for one combination of species, Amphiprora cf. paludosa and Navicula salinarum, under several of the test conditions. Such conditions either resulted in co-existence or the almost complete exclusion of one species. For example, $A$. cf. paludosa became clearly dominant at a temperature of $20^{\circ} \mathrm{C}$ and at a salinity of $34 \%$. N. salinarum predominated at the low salinity and low temperature.

Fig. 3 summarizes the observations of the competition experiments for the 3 test species and shows how specific the interactions are. Navicula salinarum was able to co-exist with Nitzschia closterium under a few conditions, as with Amphiprora cf. paludosa, and reached dominance at a low salinity and also at a low temperature. In contrast, in experimental series with various supplies of bicarbonate, $N$. salinarum is outnumbered by $N$. closterium. This may be a densitydependent effect of $N$. closterium populations; as soon as the population reached a density of $2.10^{6}$ cells cm-2, the population of $N$. salinarum collapsed. A. cf. paludosa was dominant in all combinations with $N$. closterium.

Monocultures of these diatom species were grown under the same sets of conditions as the mixed culture. Fig. 3 gives cell division rates in exponentially growing monocultures for comparison with the results of the competition experiments. Only under one condition, a salinity of $1 \%$, the outcome of the competition seems to be caused by the inability of 2 species, Amphiprora cf. paludosa and Nitzschia closterium, to grow under this condition. In most other cases the outcome of the competition is not predictable from the division rate in the exponential growth phase of monocultures. Even more, there are apparent discrepancies such as the dominance of the slowly dividing species, $A$. cf. paludosa over the more rapidly dividing $N$. salinarum and the invariable dominance of $A$. cf. paludosa over $N$. closterium.

It is evident from Fig. 3 that in addition to several cases of coexistence of species, there is also a strong tendency towards segregation of species.

Three observations indicate the existence of an inhibitory substance in the case of the competition between Amphiprora cf. paludosa and Nitzschia closterium. Firstly, extracts of $A$. cf. paludosa cultures caused microscopically visible deterioration of $\mathrm{N}$. closterium cells within a few hours. Secondly, addition of extract interrupted the growth of $N$. closterium cultures for approximately $2 \mathrm{~d}$. Thirdly, the dominance of $A$. cf. paludosa over $N$. closterium had a clear threshold of population density. When a competition experiment with the 2 species was started with 20 -fold numerical dominance of $N$. closterium the other species, $A$. cf. paludosa, developed slowly (Fig. 4). As soon as the numbers of the latter species exceeded ca. $10^{6}$ cells $\mathrm{cm}^{-2}$, the population of $N$. closterium deteriorated. This competition experiment is also compatible with the postulated chemical nature of the interspecific interaction between $A$. cf. paludosa and $N$. closterium. 


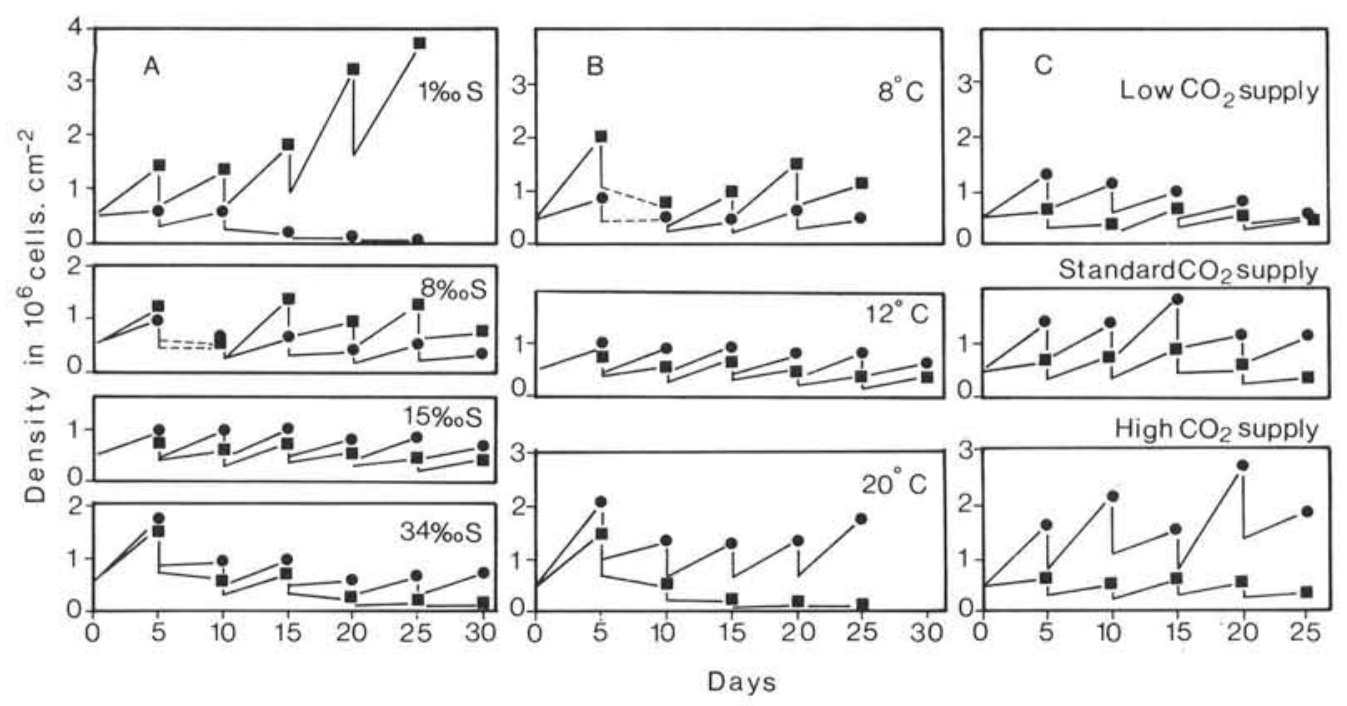

Fig. 2. Competition between Amphiprora cf. paludosa $(\bullet)$ and Navicula salinarum (घ) in serially diluted mixed cultures. Cultures kept at various salinities at a fixed temperature of $12^{\circ} \mathrm{C}$ and under standard $\mathrm{CO}_{2}$ supply (A), at various temperatures and a fixed salinity of $15 \%$ and under standard $\mathrm{CO}_{2}$ supply (B), and incubated at 3 gradations of $\mathrm{CO}_{2}$ supply at $12{ }^{\circ} \mathrm{C}$ and $15 \%(\mathrm{C})$

A.pal. $\times$ N.sal.

$$
\begin{aligned}
& \text { condition } \\
& 1 \% \circ S \\
& 8 \% \circ S \\
& 15 \% \circ S \\
& 34 \% \circ S
\end{aligned}
$$
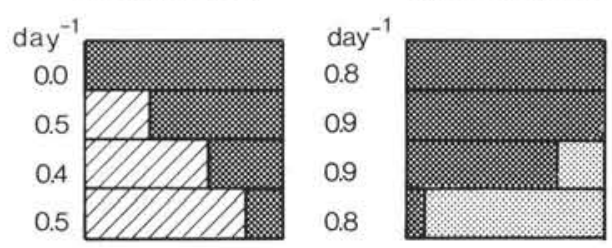

$8{ }^{\circ} \mathrm{C}$

$12{ }^{\circ} \mathrm{C}$

$20^{\circ} \mathrm{C}$
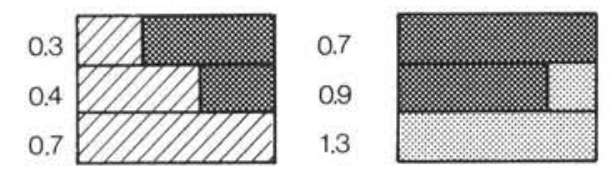

1.3

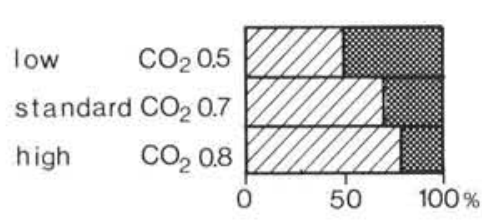

0.8
0.8
0.8

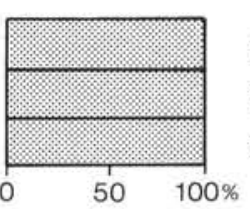

A cursory examination showed that $N$. closterium had a similar chemical effect on $N$. salinarum. However, this interaction was somewhat less pronounced and did not prevent $N$. salinarum from becoming dominant in some of the mixed cultures with $N$. closterium (Fig. 3).

\section{DISCUSSION}

\section{Depletion of inorganic carbon}

The depletion of $\mathrm{CO}_{2}$ among planktonic algae has often been demonstrated for freshwater communities (e.g. Goldman, 1973; Talling, 1976; Jaworski et al.,

N.clos. $\times$ A.pal.
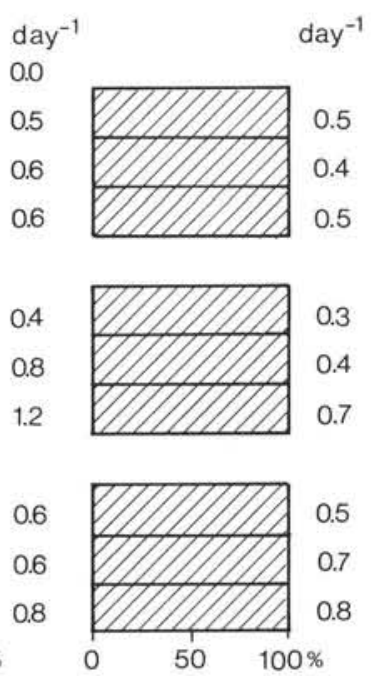

Fig. 3. Numerical abundance (\%) of individual species after a $25 \mathrm{~d}$ period of incubation in mixed cultures. Environmental conditions as in legend of Fig. 2. Numbers refer to division rates $\left(\mathrm{d}^{-1}\right)$ in the exponential growth phase, realised by species in monocultures kept under the same incubation conditions. Hatched: Amphiprora cf. paludosa; cross-hatched: Navicula salinarum; dotted: Nitzschia closterium

1981). It is less likely that $\mathrm{CO}_{2}$ will be depleted in estuarine and marine environments because there are usually large amounts of inorganic carbon in seawater. In communities of freshwater and estuarine benthic diatoms respectively, McIntire (1968) and Admiraal et al. (1982) have demonstrated carbon-limited growth. In nutrient-rich conditions this kind of nutrient limitation seems to prevail over the more commonly investigated shortage, e.g. of phosphate and nitrogen. Hence, we expect the fixation of inorganic carbon by benthic diatoms to be a critical factor in the competition in dense mats.

Morris (1980) distinguished 2 processes in carbon assimilation: (1) fixation in the Calvin Benson cycle; (2) $\beta$-carboxylation of $\mathrm{C}_{3}$ compounds, forming TCA- 
cycle intermediates. Marine algae show a spectrum of metabolic types based on the degree to which the Calvin Benson cycle is supplemented with the socalled $\mathrm{C}_{4}$-metabolism (Morris, 1980). In addition, uptake of anorganic carbon varies among species: some use $\mathrm{CO}_{2}$ exclusively, others utilize both $\mathrm{CO}_{2}$ and $\mathrm{HCO}_{3}{ }^{-}$, and some species prefer $\mathrm{HCO}_{3}{ }^{-}$(Beardall et al., 1976; Mukerji et al., 1978; Morris, 1980). A few

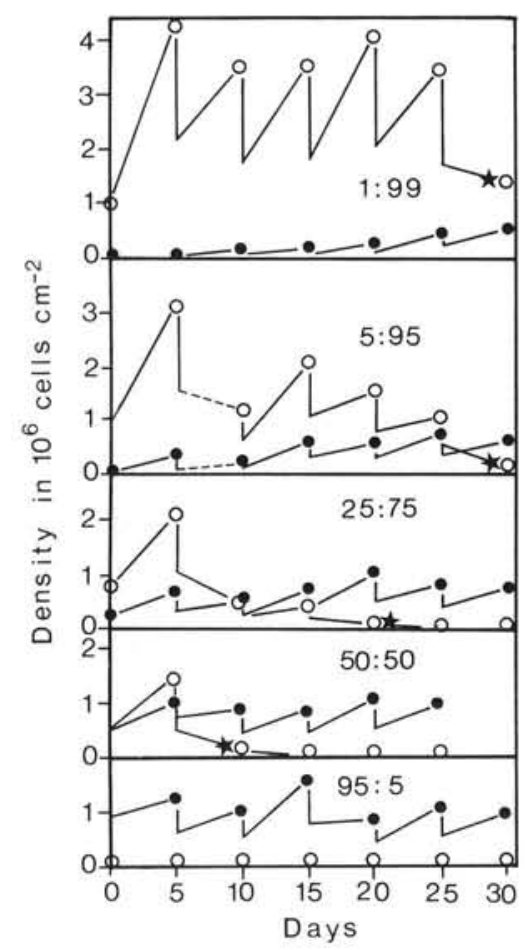

Fig. 4. Competition between Amphiprora cf. paludosa (•) and Nitzschia closterium $(0)$ in serially diluted cultures inoculated with ratios of $1: 99,5: 95,25: 75,50: 50$, and $5: 95$. ${ }^{*}$ dead cells observed. Temperature: $12{ }^{\circ} \mathrm{C}$; salinity: $15 \%$

indications on the nature of carbon fixation by benthic diatoms are reported by Glover, Zingmark, Griffith and Morris (1979, unpubl.). They showed a parallel utilization of extracellular $\mathrm{CO}_{2}$ and $\mathrm{HCO}_{3}{ }^{-}$in Amphiprora cf. paludosa, Surirella ovata and Navicula pelliculosa. In addition, a conspicuous activity of the phosphoenolpyruvatecarboxylase and $\mathrm{C}_{4}$-type fixation patterns was found in these diatoms. Unlike $N$. pelliculosa the first two species did not show increasing $\mathrm{C}_{4}$-characteristics in dense cultures. We hypothesized that this might be related to their partly planktonic way of life: $A$. cf. paludosa, S. ovata (and Nitzschia closterium) are easily suspended species, frequently found in estuarine plankton. Navicula species, in the present work $N$. salinarum, more often form dense mats on intertidal muds and might therefore be adapted to a variable supply of inorganic carbon. This hypothesis was not unequivocally supported by the present observations: $A$. cf. paludosa and $N$. closterium were able to co-exist with $N$. salinarum.

Revsbech et al. (1980) showed that the oxygen concentration in the top layer of marine sediment fluctuates from very low values to supersaturation. Ludden et al. (1984) explored how cells might cope with large fluctuations in oxygen saturation, inorganic carbon concentration and $\mathrm{pH}$ in the micro-habitat of an algal film. Observations by Revsbech et al. (1980) and Ludden et al. (1984), together with our observations, reveal the need for new experiments on carbon fixation in diatom species that dominate the intertidal habitat.

\section{Co-existence of species}

Apparently, co-existence of 2 diatom species, as found in several of the present serially diluted cultures, contradicts the microbiological axiom that only one organism becomes dominant under a given set of conditions. Basically, the observed co-existence over the ecologically relevant time span of $25 \mathrm{~d}$ can be explained by the fact that the environmental conditions imposed were neither constant in time nor in space. Firstly, the nature of the limiting factor, inorganic carbon supply, is accompanied by related factors such as a variable $\mathrm{pH}$ and oxygen saturation. The species might show responses to the intercorrelated factors, which differ from the response to a single limiting substrate. Secondly, the distribution of the cells over the bottom of culture flask was patchy. The spatial heterogeneity thus formed allowed separation of species and gave them the opportunity of shaping their own microniche (McIntire, 1968; Levin, 1974). Thirdly, the populations were subjected to light-dark cycles and were diluted only at intervals. The temporally heterogenous conditions might lead to periods of favourable conditions for one species alternating with periods favourable for another species. In the same way Turpin and Harrison (1979) showed the influence of the irregular addition of a single limiting nutrient. When culturing two phytoplankton species at a growth-rate of $0.3 \mathrm{~d}^{-1}$ in continuous culture, they found that the regime of nutrient addition altered the relative abundance of species, allowing the co-existence at intermediate nutrient 'patchiness'.

Assemblages of benthic diatoms by their mode of life are likely to show much temporal and spatial heterogeneity even under experimental conditions. This heterogeneity, and the supposed microniches associated with it, might be responsible for the large numbers of species that are usually found in the same assemblages from intertidal flats and for the very large numbers of benthic diatom species in general. 
Effects of interspecific competition on the distribution of species

The present experiments reveal which relatively simple interactions cause density-dependent factors to interfere with the distribution of species over environmental gradients. The existence of density-dependent factors in nature is indicated by the negative correlations between the species diversity and the density of benthic diatom populations (Brown and Austin, 1973; Colijn and Dijkema, 1981; Admiraal et al., 1984). Another indication is provided by the similarity between the population density in our step-wise diluted cultures and that in well developed natural communities. A clear example of the severe impact of interspecific competition is found by the response of Navicula salinarum. This species forms monocultures on a brackish mudflat during the colder seasons (Admiraal et al., 1984). In monocultures it grows rapidly at temperatures of $20^{\circ} \mathrm{C}$ and salinities of $34 \%$ and higher. Nevertheless, in competition with the 2 other test species it was only dominant under conditions at which it reached its dominance in nature. The other species, Nitzschia closterium (and an unidentified Amphiprora species), are mentioned as warm water species by Smayda (1980). Generally the ecological range of the 3 diatom species was appreciably narrowed when they were confronted with severe competition for inorganic carbon and also had to cope with very high concentrations of oxygen in the immediate vicinity of the cells.

A special case may be interaction of antibiotic substances produced by individual diatom species. The direct packing of several cell layers in the populations increase the likelihood of allelopathetic interaction occurring among the species, whereas in the phytoplankton a large volume of water may dilute the active substances. Our experiments demonstrate how selective this interaction can be. Nitzschia closterium died in mixed cultures with Amphiprora cf. paludosa, whereas Navicula salinarum was able to coexist with A. cf. paludosa and hence seemed to be insensitive to the antibiotic factor produced by the latter species. The inhibitory effect exerted by $A$. cf. paludosa could have been modified or even been effected by the bacterial contaminant in this culture, but the clear relation between the concentration of $A$. cf. paludosa cells and the inhibitory effect did not indicate this. However, it is clear that the interaction of benthic diatom species and diatom bacteria interaction should be investigated collectively in future studies. So far it is not possible to compare the present observations on allelopathy in cultured diatom species with their distribution in nature.
Acknowledgements. We are indebted to Harry Peletier for supporting the experiments and to Dr. H. van Gemerden, Ir. L. Bouwman and Professor C. van den Hoek for critical comments on the manuscript. J. Burrough-Boenisch improved the English text.

\section{LITERATURE CITED}

Admiraal, W., Peletier, H. (1980). Distribution of diatom species on an estuarine mudflat and experimental analysis of the selective effect of stress. J. exp. mar. Biol. Ecol. 46: $157-175$

Admiraal, W., Peletier, H., Zomer, H. (1982). Observations and experiments on the population dynamics of epipelic diatoms from an estuarine mudflat. Estuar. coast. Shelf Sci. 14: 471-487

Admiraal, W., Peletier, H., Brouwer, T. (1984). The seasonal succession patterns of diatom species on an intertidal mudflat: an experimental analysis. Oikos 42: 30-40

Beardall, J., Mukerji, D., Glover, H. E., Morris, I. (1976). The path of carbon in photosynthesis by marine phytoplankton. J. Phycol. 12: 409-417

Brown, S. D., Austin, A. P. (1973). Diatom succession and interaction in Littoral periphyton and plankton. Hydrobiologia 43: 333-356

Colijn, F., Dijkema, K. (1981). Species composition of benthic diatoms and distribution of chlorophyll a on an intertidal flat in the Dutch Wadden Sea. Mar. Ecol. Prog. Ser. 4: 9-21

Elbrächter, M. (1977). On population dynamics in multispecies cultures of diatoms and dinoflagellates. Helgoländer wiss. Meeresunters. 30: 192-200

Fedorov, V. D., Kustenko, N. G. (1972). Competition between marine planktonic diatoms in mono- and mixed cultures. Oceanologia 12: 91-100

Goldman, J. C. (1973). Carbon dioxide and pH: effect on species succession of algae. Science, N.Y. 182: 306-307

Jaworski, G. H. M., Talling, J. F., Heaney, S. I. (1981). The influence of carbon dioxide depletion on growth and sinking rate of two planktonic diatoms in culture. Br. phycol. J. 16: $395-410$

Kayser, H. (1979). Growth interactions between marine dinoflagellates in multispecies culture experiments. Mar. Biol. 52: $357-369$

Lange, W. (1974). Competitive exclusion among three planktonic bluegreen algal species. J. Phycol. 10: 411-414

Levin, S. A. (1974). Dispersion and population interactions. Am. Nat. 108: 207-228

Ludden, J. D. H., Admiraal, W., Colijn, F. (1984). Cycling of carbon and oxygen in layers of marine microphytes: a simulation model and its eco-physiological implications. Limnol. Oceanogr., submitted

McIntire, D. C. (1968). Physiological-ecological studies of benthic algae in laboratory streams. J. Wat. Pollut. Control Fed. 40: 1940-1952

Morris, I. (1980). Path of carbon assimilation in marine phytoplankton. In: Primary productivity in the sea. In: Falkowsky, P. G. (ed.) Environmental science research, Vol. 19. Plenum Press, New York, p. 139-157

Mukerji, D., Glover, H. E., Morris, I. (1978). Diversity in the mechanism of carbon dioxide fixation in Dunaliella tertiolecta. J. Phycol. 14: 137-142

Patrick. R. (1977). Ecology of freshwater diatoms and diatom communities. In: Werner, D. (ed.) The biology of diatoms. Botanical monographs, Vol. 13. Blackwell, Oxford, p. 284-332

Revsbech, N. P., Sørensen, J., Blackburn, T. H., Lomholt, J. P 
(1980). Distribution of oxygen in marine sediments measured with microelectrodes. Limnol. Oceanogr. 25: 403-411

Russell, G., Fielding, A. H. (1974). The competitive properties of marine algae in culture. J. Ecol. 62: 689-698

Sharp, J. H., Underhill, P. A., Hughes, D. J. (1979). Interaction (allelopathy) between marine diatoms: Thalassiosira pseudonana and Phaeodactylum tricornutum. J. Phycol. 15: $353-362$

Smayda, T. (1980). Phytoplankton species succession. In: I.
Morris (ed.) The physiological ecology of phytoplankton. Blackwell, Oxford, p. 493-570

Talling, J. F. (1976). The depletion of carbon dioxide from lake water by phytoplankton. J. Ecol. 64: 79-121

Tilman, D. (1978). The role of nutrient competition in a predictive theory of phytoplankton population dynamics. Mitt. int. Verein. theor. angew. Limnol. 21: 585-592

Turpin, D. H., Harrison, P. J. (1979). Limiting nutrient patchiness and its role in phytoplankton ecology. J. exp. mar. Biol. Ecol. 39: 151-160

This paper was submitted to the editor; it was accepted for printing on April 20, 1984 